\title{
AKSELERASI-INKLUSI DALAM PERSPEKTIF LAYANAN EFEKTIF ANAK BERBAKAT
}

\author{
Yuyus Suherman \\ e-mail: yuyus@upi.edu \\ Universitas Pendidikan Indonesia
}

\begin{abstract}
Abstrak: Pentingnya pendidikan khusus bagi anak berbakat, disadari banyak kalangan. Tetapi implementasi pendidikan khusus melalui kelas akselerasi mengundang polemik. Berkenaan dengan hal tersebut, akselerasi perlu dikembalikan pada gagasan awal sebagai upaya untuk memberi layanan efektif bagi anak berbakat. Ini penting, sebab meskipun namanya kelas akselerasi, esensi akselerasi tidak terjadi. Kelas akselerasi juga hanya menyentuh anak berbakat berprestasi dan ber-IQ tinggi, tidak menyentuh anak berbakat berprestasi rendah dan tidak beruntung. Esensi akselerasi terletak pada layanan efektif bagi anak berbakat. Salah satu terobosan inovatif adalah akselerasi-inklusi. Dalam konteks pendidikan inklusif akselerasi adalah keharusan, karena disinilah esensi pemenuhan kebutuhan khususnya. Tulisan ini mengkaji akselerasi-inklusi di SD Al-Mabrur Bandung Jawa Barat. Fokus kajian diarahkan pada apa, mengapa, dan bagaimana akselerasi-inklusi yang dikembangkan dalam program pembelajaran 5 tahun dan full-day school tersebut, relevan dengan konteks layanan efektif anak berbakat.
\end{abstract}

Kata kunci: akselerasi, anak berbakat, inklusi, layanan efektif, terobosan inovatif.

\section{ACCELERATION-INCLUSION IN THE PERSPECTIVE OF EFFECTIVE GIFTED CHILDREN SERVICE}

\begin{abstract}
Many people realize the importance of special education for gifted and talented children. However, the implementation of special education through accelerated class generates a polemic. In regards to the problem mentioned above, the acceleration should be laid upon the original idea as an effort to effectively serve the gifted and talented children. This is crucial, since this is called as an accelerated class, where acceleration has to take place. The accelerated class seems to be meant only for talented children with such an achievement and a high score of IQ, but the accelerated class is neither for children with under achievement or the disadvantaged children. While it's mentioned legally that every citizen has the right to access education. The essence of acceleration lies in the effective service for gifted and talented children. One innovative is accelerated-inclusion. In the context of inclusive education, the acceleration is a must, as this is the essence of the fulfillment of the special needs. This article analyzed accelerated-inclusion in Al-Mabrur Elementary School, in Bandung. The focus of the analysis is what, wh, and how the accelerated-inclusion is developed in this five-year learning program full-day school, and is relevant to the context of effective service for gifted and talented children.
\end{abstract}

Keywords: accelerated, inclusive, effective service, innovative, gifted and talented children.

\section{PENDAHULUAN}

Program akselerasi bagi anak berbakat $(\mathrm{CI}+$ BI) sejak awal disadari mengundang pro-kontra. Mereka yang pro, berargumen dengan aspek legalyuridis dan kebutuhan anak berbakat akan pendidikan yang sesuai. Mereka juga menyatakan anak berbakat beresiko berprestasi rendah (underachiever), sehingga kelas "khusus" akselerasi diyakini sebagai solusinya. Di sisi lain, sikap kontra muncul atas pemikiran bahwa kelas khusus, mengarah pada pembentukan masyarakat elit. Kalangan pakar pendidikan menyatakan pengelompokan anak secara homogen berdasarkan kemampuan akademik menjadi kelas super baik, sampai kelas kurang baik, tidak memiliki dasar filosofi, apalagi disertai degradasi.

Upaya menggebu menyelenggarakan pendidikan khusus bagi anak berbakat dalam berbagai bentuk, dan polemik berkepanjangan, menunjukan belum adanya konsensus tentang bagaimana anak berbakat dididik. Fenomena kelas akselerasi (Direktorat Pendidikan Khusus-Layanan Khusus), Cugenang Gifted School (Yayasan Kinarya Didaktika), dan sejenisnya, di satu sisi merupakan bentuk tanggung jawab pendidikan anak berbakat, tetapi di sisi lain hal ini bertentangan dengan komitmen pendidikan inklusif 5 tahun. Salamca Statement dalam kajian aktivitas UNESCO (1999) memperingatkan, meskipun maksudnya baik, 
institusi khusus adalah eksklusi.

Pentingnya pendidikan khusus bagi anak berbakat, diterima banyak kalangan. Esensi masalahnya memang tidak di pentingnya itu, tetapi implementasi pendidikan khusus melalui kelas "khusus" akselerasi inilah yang mengundang polemik. Argumentasi jika anak berbakat berada di kelas biasa, akan kehilangan semangat belajar karena jenuh, tidak relevan dengan solusinya. Jika proses belajarnya tidak berkualitas, semua anak dipastikan akan mengalami kejenuhan. Karena itu, solusinya dengan memperbaiki kualitas pembelajaran, bukan dengan kelas "khusus" akselerasi. Dengan demikian, hal mendasar untuk mengahiri polemik adalah dengan kembali ke filosofi pendidikan. Melalui pemahaman yang benar terhadap filosofi pendidikan, maka konsensus bagaimana anak berbakat dididik dapat terwujud.

Berkenaan dengan hal itu, progam akselerasi anak berbakat perlu dikembalikan pada gagasan awal sebagai upaya memberi layanan pendidikan efektif, agar potensinya berkembang optimal. Hal ini menuntut evaluasi terhadap implementasi program akselerasi dalam bentuk kelas khusus. Ini penting, sebab meskipun kelas "khusus" akselerasi diklaim sebagai wahana pembinaan anak berbakat, tetapi esensi akselerasinya tidak terjadi. Selain itu, akselerasi dalam bentuk kelas "khusus' hanya menyentuh anak berbakat berprestasi dan ber-IQ tinggi, tidak menyentuh anak berbakat berprestasi rendah dan tidak beruntung, padahal aspek legal-undang undang berbicara "warga negara" tanpa kecuali. Jika kembali pada aspek legal-undang undang, implementasi pendidikan khusus anak berbakat belum berada di jalan yang benar. Untuk kembali ke jalan yang benar, kajian keberbakatan dan pendidikan khusus harus ditamatkan, tidak hanya berkutat pada aspek legalyuridis saja, tetapi kajiannya harus mencakup aspek filosofis dan historis agar utuh dan tidak kehilangan konteks.

Dari perspektif filosofis -historis, keberbakatan (giftedness) telah menjadi isu menarik sepanjang sejarah. Setiap kebudayaan memiliki imajinasi sendirisendiri dan terus berkembang secara dinamis seiring perkembangan filosofisnya. Pada zaman Yunani, keberbakatan dikaitkan dengan keahlian berpidato, sedangkan pada zaman Romawi keberbakatan dikaitkan dengan keahlian berperang (Kirk \& Gallagher, 1990). Untuk waktu lama, keberbakatan mengacu pada konsep Terman, yang mengacu pada IQ; kemudian Guilfor menambah dengan aspek kreativitas; serta Marland, menambahkan lagi dengan aspek kepemimpinan, kemampuan seni visual, dan gerak. Selanjutnya Renzuli melalui the three ring conception-nya lebih menegaskan kembali bahwa keberbakatan merupakan interaksi fungsional antara tiga kluster, yaitu kemampuan umum di atas rata-rata, kreativitas, dan komitmen terhadap tugas yang tinggi. Tetapi kemudian Renzulli mengoreksi kemampuan umum diatas rata-rata, menjadi kemampuan diatas rata-rata bermakna kemampuan umum dan kemampuan khusus (Rochmat Wahab,2009).

Penggunaan the three ring conception Renzuli, disadari tidak menyentuh seluruh populasi anak berbakat, seperti anak berbakat underachiever, yaitu memiliki kesenjangan antara domain kemampuannya berdasarkan tes kecerdasan baku, dan anak berbakat dengan disabilitas. Karena itu kemudian berkembang konsep the triadich-Renzulli-Mönks (Sternberg,at. al.1986), dikenal sebagai model multifaktor. Menurut model ini, keberbakatan yang dikonsepkan Renzuli tersebut tidak akan terwujud jika tidak mendapat dukungan sekolah, keluarga, dan lingkungan .

Dinamika konsep keberbakatan terus berlanjut, Monk mengembangkan model multifactor dan menyatakan bahwa keberbakatan mencakup empat dimensi multifaktor yang saling terkait yaitu : faktor talenta, kinerja, kepribadian dan lingkungan. Faktor talenta mencakup tujuh area: kemampuan intelektual, kemampuan kreatif, kompetensi sosial, kecerdasan praktis, kemampuan artistik, musikalitas, dan keterampilan psikomotor. Faktor kinerja meliputi delapan area yaitu: matematika, IPA, teknologi, komputer, seni, bahasa, olah raga, serta relasi sosial (Heller,2000).

Dengan adanya dinamika konsep keberbakatan tersebut, maka sudah selayaknya semua kalangan baik akademisi, birokrasi dan praktisi berpikir ulang untuk merumuskan konsep yang utuh secara filosofis, historis dan yuridis, sehingga sampai pada konsensus tentang siapa anak berbakat itu, dan bagaimana anak berbakat dididik. Hal ini penting adanya sebab konsep keberbakatan merupakan dasar membuat definisi anak berbakat, dan bedasarkan definisi ini ciri-ciri anak berbakat dapat dirumuskan. Melalui ciri-ciri tersebut anak berbakat dapat diidentifikasi dengan tepat. Setelah anak berbakat diidentifikasi dengan benar, maka konteks kebutuhan khususnya juga dapat diasesmen untuk selanjutnya dijadikan dasar pembuatan diversifikasi program yang sesuai dengan kebutuhan uniknya. Berikutnya melalui program pembelajaran yang diindividualkan (PPI) akselerasi dalam seting inklusi sebagai pilihan program untuk kepentingan terbaik anak berbakat dapat diimplementasikan. 
Implementasi akselerasi dalam seting inklusi disadari membawa banyak konsekuensi yang membutuhkan penjelasan dan jawaban operasional. Konsep dan konteks akselerasi serta perspektif menuju inklusi disadari tidak mudah dicerna dan dipahami karena menyangkut pergeseran paradigma pendidikan yang mendasar sebagai konsekuensi perubahan filosofi penidikan yang dianutnya. Untuk itu sebelum sampai peda pemahaman yang benar, maka diperlukan pengkajian kebali terhadap pendidikan khusus sebagai ilmu, sehingga praktek pendidikan khusus yang berkembang dapat dilihat dengan jelas keberadaannya, apakah berada dijalan benar atau berada dijalan yang salah.

Sebagai ilmu, pendidikan khusus terus berkembang dinamis, tetapi sebagai praktik pendidikan khusus masih berjalan ditempat, sehingga hakikat pendidikan khusus termasuk terminologi to word inclusion, perlu dimaknai secara utuh. Hal ini penting, sebab konsep pendidikan khusus selama ini dimaknai secara keliru. Kondisi tersebut dimungkinkan karena diabaikannya aspek filosofis dan historisnya. Pendidikan khusus hanya dipahami dari aspek legal-yuridis, yang kebetulan juga keliru. Secara historis terminologi pendidikan luar biasa (orthopedagogik) lebih dominan ketimbang pendidikan khusus (special education) meskipun aspek legal-yuridis kini memihak pendidikan khusus. Ini karena orthopedagogik (Belanda) 1 ebih awal hadir ketimbang special education (Inggris) dalam wacana pendidikan di Indonesia.

Sebagai ilmu, pendidikan khusus mewarisi kriteria ilmu pendidikan dalam memandang manusia dan cara mengembangkan potensinya. Pandangan tentang manusia yang diterima ilmu pendidikan, merupakan mahluk individual tetapi berkarakteristik sosial dan etis. Dengan demikian sebagai manusia semua anak diyakini dapat dididik. Di sisi lain berkembang pandangan manusia sebagai mahluk sosial. Menurut pandangan ini perkembangan anak sangat bergantung pada interaksi dengan lingkungan, sehingga pendekatan ini dikenal sebagai pendekatan ekologi, pendekatan sistem dan pendekatan management. Sebagai bagian ilmu pendidikan, pendidikan khusus juga mendasarkan bahan pelajaran pada teori perkembangan anak, dikenal dengan pendekatan developmental. Tetapi pada kenyataannya bahan pelajaran tidak selalu mengikuti urutan, mundur atau meloncat ke bahan berikutnya (Suhaeri Harja Natawiyoga, dkk, 1997).

Di Indonesia, praktik pendidikan khusus secara formal dimulai dengan berdirinya blinden instituut tahun 1901, dan lembaga khusus doofstommen instituut tahun 1930, keduanya di Bandung. Ketika Indonesia merdeka, pemerintah membentuk seksi bahasa asing untuk urusan sekolah dasar. Seksi ini, selain diserahi pembinaan pengajaran bahasa asing, diserahi pembinaan sekolah khusus (SLB). Inilah kesalahan sejarah pertama, sehingga muncul kesan pendidikan khusus (PLB) hanya urusan sekolah dasar. Dengan masuknya pendidikan khusus dalam undangundang dan dibukanya jurusan pendidikan khusus (PLB) di perguruan tinggi, jenis yang tercakup dalam pendidikan khusus juga berkembang (Suhaeri Harja Natawiyoga,dkk, 1997).

Sementara itu dalam konteks praktik pendidikan anak berbakat di Indonesia, disadari masih ketinggalan, karena hingga kini belum memiliki konsensus. Padahal, pendidikan anak berbakat ini sangat penting dan mendesak adanya. Hal ini didasarkana pada pemikiaran bahwa anak berbakat mewakili masa depan masyarakatnya. Dari barisan mereka ilmuwan, penulis, seniman akan hadir memberi kontribusi untuk kemajuan masyarakat dan kepemimpinan dunia. Mengabaikan anak berbakat, berarti membiarkan masyarakat masa depan tetap menjadi masyarakat kelas bawah (Heller, Monks, Sternberg, \& Subotnik, 2000).

Dinamika pendidikan khusus anak berbakat, tidak lepas dari dinamika pendidikan khusus dalam konteks " anak khusus " lainnya. Secara historis lebih dari 20 negara maju memasukan anak berbakat pada kategori anak luar biasa (exceptional) yang memerlukan pendidikan khusus . Awalnya, hal tersebut lebih banyak didasarkan pada pertimbangan ekonomis, mengingat kategori exceptional ini menguntungkan, karena masuk kelompok yang mendapat jaminan lebih baik dari sudut anggaran (Kirk,et.al,2006). Konteks pendidikan khusus anak berbakat mencerminkan komitmen memperluas kesempatan belajar bagi anak berbakat. Dengan demikian diferensiasi pembelajaran anak berbakat, menjadi penting karena tiga sifat berikut: (1) Anak berbakat memiliki kepentingan berbeda dari anak lain. (2) Anak berbakat memiliki kemampuan mempelajari pelajaran baru lebih cepat, (3) Anak berbakat belajar banyak dalam pelajaran yang mereka pelajari (Piirto,1994 dalam Smith,2006).

Mengacu pada konsep pendidikan khusus, maka praktik penyelenggaraan pendidikan khusus bagi anak berbakat cukup beragam. Hal ini dimungkinkan karena pilihannya tersedia cukup banyak, dari mulai yang segeratif hingga yang integratif, semuanya bersifat eklusif. Hal tersebut tersaji secara lengkap pada gambar 1 . 


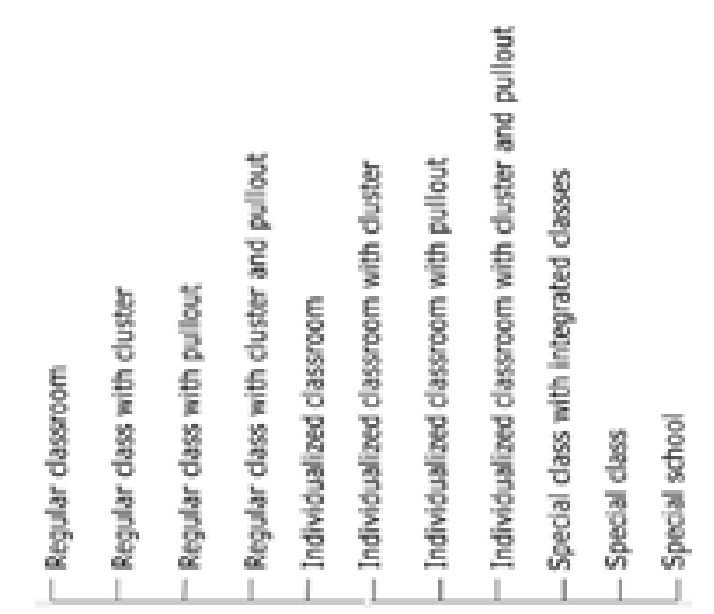

Gambar 1. Continuum Model for Ability Grouping (Clark,1983:148)

Sejak tahun 1980-an, pendidikan khusus anak berbakat menjadi wacana. Uji coba yang dilakukan di Jakarta dan Cianjur, selain kriteria keberbakatan yang dipertanyakan, pro-kontra muncul karena perlakuan khusus dinilai tidak sesuai dengan prinsip demokrasi pendidikan. Kekhawatiran munculnya eklusivisme, banyak dilontarkan. Kritikan terhadap pendidikan eklusif memuat beberapa poin: (1) sifat esensial sekolah/kelas eklusif tidak memiliki sense of community (2) pesannya, jika berbeda, anak harus angkat kaki dapat menantang sense of secure anak ; (3) anak yang dipilih untuk program berbakat dapat menciptakan suasana terasing dan ketidak percayaan di antara anak; (4) anak mendapat program yang menciptakan kekacauan kegiatan kelas dan kesulitan lebih besar bagi guru untuk mencipakan sense of cohesiveness; (5) mengambil anak dari kelas umum untuk memenuhi kebutuhan anak berbakat, mengurangi sense of competence guru dalam memberi pengajaran dalam kelompok beragam (Sapon-Shevin,1995 dalam Smith 2006)

Untuk menemukan nilai-nilai kehidupan, relevansi sekolah dipahami dengan belajar melalui masyarakat. Desain ini mendorong kebijakan pintu terbuka dengan orang yang bisa dipanggil ke sekolah untuk tujuan khusus. Dengan demikian, sekolah tidak hanya berada dalam masyarakat, tetapi harus dilihat sebagai komunitas. Sedangkan untuk menemukan potensi keberbakatan, difasilitasi dengan kesempatan melihat dan mengatasi masalah sosial yang dilakukan secara interdisipliner. Dua hal penting di studi interdisipliner: pertama, studi tematik seperti kekerasan, polusi, dan sebagainya; kedua, adalah kegiatan penelitian individu dan kelompok kecil. Hal penting lainnya adalah ketersediaan kesempatan untuk terlibat dengan materi menantang. Pengembangan kurikulum berdiferensiasi bertolak dari asumsi bahwa setiap individu berbeda kecepatan perkembangannya, dan pengabaian hal ini akan mengganggu perkembangannya.

Istilah diferensiasi merujuk pada kurikulum yang tidak berlaku umum, dirancang untuk memenuhi kebutuhan bakat tertentu dan perkembangan kreativitas individu (Conny Semiawan, 1996). Dengan mendiferensiasikan kurikulum, anak berbakat memperoleh pembelajaran bermakna. Hal ini berdampak terhadap perkembangan intelektual dan emosionalnya. Kurikulum yang sesuai dengan tingkat kemampuan anak memberi kepuasan dan tantangan. Anak berbakat belajar materi baru, sehingga mereka menjadi lebih aktif, tidak bosan, dan terhindar dari underachiever. Melalui informasi, proses, dan sumber beragam sesuai kebutuhan dan minat anak. Clark (Utami Munadar,2012) menyatakan, hal yang penting diperhatikan yaitu: materi dipercepat, bekerja dengan konsep dan pemikiran abstrak, waktu belajar untuk tugas rutin dipercepat, dan waktu mendalami topik lebih lama, dan lebih menantang.

Parke (dalam Utami Munandar,2012) memberi pedoman untuk memudahkan transisi dari cara belajar lama ke yang baru, yaitu: mulai dengan bidang studi atau satu kelompok anak yang minat dan kemampuannya setara, secara berangsur-angsur ditambah lebih banyak bidang studi dan lebih banyak anak. Berikutnya, buat bagan untuk mendaftar program dan modifikasi kurikuler yang dapat digunakan untuk masing-masing program. Program dapat dimodifikasi dalam banyak cara. Setiap program alternatif harus memberi kesempatan berkembang.

Seirng dianutnya filosofi inklusi, yaitu suatu keyakinan fundamental bahwa setiap individu dapat belajar, tumbuh, dan bekerja dengan semua orang, baik di sekolah, di lingkungan kerja dan di masyarakat. Konteks pendidikan anak berbakat dalam seting eklusif menjadi tidak relevan lagi kalau tidak dikatakan ketinggalan zaman. Kelas khusus akselerasi yang eklusif untuk anak berbakat ( CI + BI) jelas bertentangan dengan filosofi inklusi. Meskipun demikian masih bannyak kalangan yang bersikukuh dengan konsep kelas khusus akselerasi ini dan mengatakan bahwa inklusi tidak cocok bagi anak CI+ BI serta mengatakan bahwa anak berbakat tidak akan berkembang jika disatukan dengan anak biasa. Hal ini dimungkinkan terjadi karena filosofi inklusi dan hakikat pendidikan anak berbakat belum difahami dengan benar.

Pendidikan inklusif dilandasi filosofi inklusi. 
Prinsip dasar pendidikan inklusif adalah menghargai perbedaan. Bila pendidikan inklusif dianut, pemikiran bahwa siswa harus jadi "normal" agar dapat berperan serta pada kehidupan harus ditinggalkan. Dengan demikian, sebagaimana dikemukakan Kunc (Smith, 2006) pendidikan inklusif merupakan wujud komitmen penyediaan kesempatan belajar bagi semua anak, lebih dekat dengan konsep peningkatan mutu sekolah.

Konteks pendidikan inklusif adalah memperluas penyediaan layanan ideal dalam pendidikan. Dalam masyarakat demokratis, pendidikan diarahkan pada penyediaan pendidikan bermutu bagi semua. Pendidikan inklusif bukan penolakan terhadap perbedaan individu, tetapiakomodasi dan pemenuhan pendidikan, kebutuhan sosial dan emosionalnya, serta pengakuan terhadap gaya belajar dan membantu semua anak agar dapat mengikuti pembelajaran. Pendidikan inklusif merupakan prinsip universal pendidikan yang memiliki implikasi dimungkinkannya diversifikasi program (Stubbs, 2002).

\section{PEMBAHASAN}

Teminologi akselerasi-inklusi mengundang banyak persepsi dan pro-kontra. Hal ini dimungkinkan karena keduanya memiliki filosofi berbeda. Tetapi jika ditelusuri, akselerasi dalam seting inklusi sejalan dengan semangat pendidikan anak berbakat dan merupakan terobosan dalam konteks menuju pendidikan inklusif (toward inclusive education) yang selama ini diwacanakan. Untuk memaknai terminologi unik akselerasi-inklusi ini, penting dipahami hakikat akselerasi dan hakikat inkulusi, berikutnya bagaimana memahami konteks dan implementasinya, sehingga akselerasi-inklusi sebagai missing link dalam perspektif toword inclusive education ini dapat dipersepsi sama untuk kepentingan terbaik anak.

Esensi akselerasi terletak pada pemberian layanan pendidikan yang relevan dengan potensi anak. Untuk itu perlu dikembangkan model akselerasi yang relevan dengan filosofi inklusi. Berangkat dari esensi akselerasi ini beberapa sekolah keluar dari format akselerasi CI+BI dan inklusi pemerintah. SD AL-Mabrur kabupaten Bandung jawa barat, misalnya, mengembangkan format akselerasi-inklusi. Pembelajaran akselerasi di SD Al-Mabrur, didesain melibatkan anak secara intenshif dan menyeluruh sehingga lebih cepat menguasai pengetahuan dan keterampilan, melalui penggunaan ragam metode, diselenggarakan dalam seting inklusi dengan diversifikasi program. (Sunaryo Kartadinata,2011).

Akselerasi-inklusi, yang dikembangkan diSD AlMabrur (2011) Bandung ini cukup unik, mengundang banyak persepsi. Hal ini dimungkinkan karena filosofinya berbeda. Tetapi di sinilah keunikannya, meski akselerasi dan inklusi memiliki filosofi berbeda, keduanya sebagaimana istilah Smith (2006) bukan hal mustahil disandingkan untuk kepentingan terbaik anak. Akselerasi-inklusi hakikatnya adalah the missing link yang selama ini dicari. Memahami the missing link ini, sangat penting agar akselerasi, dan inklusi didudukan secara proposional. Program yang dikembangkan adalah program pembelajaran 5 tahun, sebagai bentuk akselerasi yang prinsipnya berlaku bagi semua anak. Bagi anak yang tidak siap mengikuti tetap belajar dengan program 6 tahun. Penyiapan program pembelajaran 5 tahun dilakukan dengan reorganisasi kurikulum, menganut pola kesetaraan perkembangan anak antara program 5 tahun dengan program 6 tahun. Di lakukan melalui asesmen kesetaraan, dalam waktu yang ditetapkan, sebagai bentuk kendali mutu proses dan hasil pembelajaran. Dinamika perbaikan mutu dilakukan dengan peningkatan standar secara bertahap.

Reorganisasi krikulum program 6 tahun ke dalam kurikulum program 5 tahun dilakukan dengan mempertimbangkan keberlanjutan kemampuan yang dikembangkan setiap mata pelajaran dari tingkatan kelas yang satu ke tingkatan kelas yang lain, dan prinsip percepatan belajar siswa. Hal ini berimplikasi kepada isi mata pelajaran dan beban belajar siswa dengan ketentuan: (1) kelas 1: 100\% program kelas satu ditambah 25\% program kelas dua; (2) kelas 2: $75 \%$ program kelas dua ditambah $50 \%$ program kelas tiga; (3) kelas 3: 50\% program kelas tiga ditambah $75 \%$ program kelas empat; (4) kelas 4: 25\% program kelas 4 ditambah 75\% program kelas lima; (5) kelas 5: $25 \%$ program kelas lima ditambah $100 \%$ program kelas enam.

Distribusi beban belajar dinyatakan dalam jam pelajaran antartingkatan kelas. Untuk mengimplementasikan beban belajar yang terkandung dalam struktur kurikulum 5 tahun, kegiatan pembelajaran dituangkan dalam rancangan waktu belajar rata-rata 9-10 jam pelajaran setiap hari. Porsi waktu setiap jam pelajaran dirancang selama 35 menit untuk kelas 1, 2, 3 dan 40 menit untuk kelas 4,5. Secara umum pola jadwal pembelajaran dirancang dari hari Senin s/d Jum'at selama 10 jam pelajaran/hari, dan hari Sabtu selama 6 jam pelajaran digunakan untuk ekstra kurikuler. Dengan demikian, dalam seminggu dirancang antara 42-58 jam pelajaran.

Pembelajaran di SD Al Mabrur berlangsung dalam sistem fullday school. Strategi pembelajaran dikembangkan dalam iklim belajar yang religius, edukatif, dan berwawasan lingkungan dan kultural. 
Esensi pembelajaran diletakkan pada upaya memfasilitasi peserta didik memiliki kemampuan belajar, kemampuan bekerja, berprestasi, hidup bermasyarakat, dan menjadi warga negara yang baik. Proses pembelajaran dirancang dan dilakukan menggunakan multistrategi, berorientasi pada prinsip pengembangan multi kecerdasan dan mengembangkan lingkungan belajar. Asesmen dilakukan secara beragam, mencakup asesmen kesetaraaan, ulangan harian, tengah semester, dan akhir semester yang hasilnya dituangkan dalam bentuk portofolio dan laporan perkembangan anak. Keunggulan diamati sepanjang proses perkembangan dan tidak divonis melalui asesmen psikologis, yang dilakukan adalah bantuan psikologis pedagogis untuk membantu anak belajar optimal.

Indikator layanan efektif bagai anak berbakat adalah sukses akademik dan non-akademik. Artinya anak berbakat dapat mengembangkan potensinya secara optimal. Hal ini tidak mungkin terjadi jika proses pembelajarannya tidak bermutu. Oleh karena itu, meningkatkan mutu dan relevansi pendidikan dasar adalah tantangan besar yang dihadapi banyak pihak saat ini, baik oleh pemerintah pusat, pemerintah daerah, maupun masyarakat. Pengetahuan tentang rancangan sekolah berkualitas berkaitan dengan pemahaman tentang kualitas pembelajaran serta di dalamnya mencakup pengetahuan konseptual dan teknikal. Pengetahuan konseptual berkenaan dengan pemahaman tentang maksud dibangunnya sekolah dan pemahaman tentang rancangan sekolah berkualitas. Pemahaman pertama berkenaan dengan perumusan visi, misi, strategi dan program yang jelas, serta tepat dan akuntabel. Pemahaman kedua berkenaan dengan prinsip rancangan konseptual sekolah berkualitas yang efektif.

Sebuah sekolah dianggap berkualitas jika proses pembelajaran dan hasilnya berkualitas, baik bidang akademik, emosional, maupun spiritual. Dari aspek biaya sebanding dengan mutu yang diperlihatkan. Sekolah ini juga memiliki etos kerja tinggi, dalam arti komunitas akademiknya biasa bekerja keras, mendidik, disiplin, tanggung jawab, objektif, dan konsisten. Dari aspek keamanan secara fisik dan psikologis terjamin, ramah lingkungan, tertib, bersih, indah, rapi dan nyaman. Berikutnya adanya suasana humanis, budaya dialog, religiusitas, moral, dan akhlak baik. Konsep kualitas ini disadari menimbulkan banyak persepsi, sehingga masyarakatpun memiliki pemahaman yang berbeda, ketika menilai sekolah berkualitas. Merupakan suatu kenaifan jika mengharapkan output sekolah berkualitas tinggi dari proses sekolah yang tidak berkualitas. Sekolah yang memastikan ketersediaan kondisi tidak memihak, adil, pantas, dan sama untuk semua siswa adalah sekolah yang memperlihatkan equitas (Lang, H.R \& Evans, D.N: 2006). Secara historis, kondisi yang equitable (adil) tergolong langka di negeri ini, apalagi jika dikaitkan dengan diversitas (keberagaman), di mana sekolah didisain untuk memenuhi kenberagaman potensi siswanya.

Persepsi masyarakat terhadap sekolah bersumber pada sejauh mana sekolah memenuhi harapan masa depan. Persepsi tersebut mendorong asumsi, hanya sekolah berkualitas yang dapat menghasilkan lulusan berdaya saing tinggi. Padahal, sampai saat ini sekolah berkualitas selain baru sebatas klaim sendiri, jumlahnya juga sedikit dan tidak jelas indikatornya. Dengan demikian diasumsikan produk sekolah yang digolongkan tidak berkualitas jumlahnya lebih banyak. Berdasarkan pemikiran inilah sekolah berkualiats bagi semua menjadi keniscayaan. Tantangan yang dihadapi pendidikan persekolahan, adalah konteks keberagaman peserta didik dan pentingnya akuntabilitas. Hal ini menjadi pemicu pengembangan sekolah berkualitas yang mampu melayani siswa sesuai keberagamannya (Arend, 2008).

Di tengah dunia yang bergerak sangat cepat, diperlukan pemikiran ulang tentang hakikat belajar dan hakikat sekolah berkualitas. Bagaimana pandangan siswa terhadap pembelajaran, guru dan sekolah, apakah mereka datang ke sekolah dengan rasa senang atau sebaliknyaa, semua itu sebagai pertanyaan awal yang menarik dalam rangka menelusuri hakikat SD berkualitas. SD berkualitas tidak lahir begitu saja. tidak lahir semata-mata karena fasilitas. Sekolah berkualitas terbentuk dari sistem yang tertata baik, dibentuk dari sebuah perencanaan yang baik, serta dilaksanakan dengan sungguh-sungguh.

Berkualitas lazim diartikan sebagai agregat karakteristik produk atau jasa yang memuaskan konsumen. Dalam konteks pendidikan, kualitas adalah suatu keberhasilan proses dan hasil belajar. Dengan demikian meningkatkan kualitas pendidikan dengan membuka akses keadilan (equitas) sembari mengobarkan revolusi pembelajaran berbasis keberagaman (diversitas) menjadi keniscayaan dan mendesak untuk dibangun dalam rangka menjalani abad 21. Tetapi ironinya, dari segi equitas pendidikan belum ditargetkan bagi semua, karena tidak sedikit warga negara usia sekolah dasar belum mengenyam pendidikan, demikian juga dari perspektif diversitas, sistem pendidikan belum menghargai keberagaman, dan kualitas tidak ditargetkan untuk semua anak. 
Dalam perspektif inilah konteks akselerasi-inklusi bagi anak berbakat relevan dikembangkan.

\section{PENUTUP}

\section{Kesimpulan}

Secara filosofi akselerasi diperuntukan bagi semua anak. Hal ini merupakan tantangan, yaitu bagaimana memungkinkan anak didik belajar lebih tinggi, lebih cepat dengan bahan bervariasi. Sementara itu inklusi dipandang sebagai seting pembelajaran akselerasi paling tepat, karena seting inklusi adalah seting alamiah. Dari perspektif filosofi, inklusi sesuai dengan hakikat pendidikan dan hakikat manusia. Seting inklusi memberikan pengalaman berharga pada anak didik untuk hidup di masyarakat inklusif. Selain itu pendidikan inklusif memberikan kesempatan pada anak kelas regular belajar keunikan anak dan belajar membangun hubungan dengan mereka. Pada gilirannya, inklusi tidak hanya sebagai seting "pembelajaran akselerasi", tetapi inklusi adalah filosofi yang sejatinya mendasari konsep pendidikan inklusif.

Di dalam konteks pendidikan inklusif akselerasi menjadi keniscayaan, karena disinilah esensi pemenuhan kebutuhan anak berbakat sebagai wujud diversifikasi program . Seting inklusi merupkan solusi bagi masalah pendidikan di Indonesia, dan ini telah menjadi komitmen nasional yang sejalan dengan komitmen internasional untuk mencapai konteks education for all (EFA), sehingga sebenarnya perdebatan itu harusnya sudah selesai, wacana kelas khusus, sekolah khusus sudah tidak perlu lagi, zaman sudah berubah, semua harus bergegas menuju inklusi, semua harus berani berubah, menata diri untuk membangun rumah bersama bernama pendidikan inklusif sebagai wahana untuk membangun masyarakat dan bangsa inklusif.

\section{DAFTAR PUSTAKA}

Arend, R. (2008). Learning to teach, belajar untuk mengajar. Alih bahasa Helly Prajitno,dkk. Yogyakarta: Pustaka Pelajar

Clark, B. (1983). Growing up gifted: Developing the potential of children at home and at school. Upper Saddle River, NJ: Merrill Prentice Hall.
Depdiknas, Ditjendikdasmen. (2003). Pedoman penyelenggaraan program percepatan belajar, SD, SMP dan SMA. ( Suatu model pelayanan pendidikan bagi peserta didik yang memiliki potensi kecerdasan dan bakat istimewa). Jakarta: Ditjen dikdasmen

Heller, K.A. et.al. (2000). International handbook of giftedness and talent. 2nd edition. Amsterdam : Elsevier Science, Ltd

Harja Natawiyoga, S dkk. (1997). Kecenderungan baru pendidikan luar biasa. Bandung : Yayasan Biruwangi

Kartadinata, S. ( 2011). Pembelajaran akselerasi dalam seting inklusi, Model pembelajaran akselerasi di SD Al-Mabrur. Bandung: Al Mabrur

Kirk \& Gallagher. (1990). Pendidikan anak luar biasa. Alih bahasa M. Amin \& Ina Yusuf K. Jakarta: DNIKS

Lang, H.R \& Evans, D.N. ( 2006). Models, strategies, and methods for effective teaching. Boston: Pearson Education, Inc

Munandar, U. (2012) Pengembangan Kreativitas Anak Berbakat, Jakarta: Rineka Cipta

Smith, J.D. ( 2006). Inclusion, School for All Student. Inklusi sekolah ramah untuk semua. Alih bahasa Denis \& Enrica, Bandung :Nuansa

Sternberg, R.J \& Davidson, J.E. ed. (1986). Conceptions of giftedness. New York: Cambridge University Press

Stubbs. (2002). Inclusive education where there are few resources, Pendidikan inklusif ketika hanya ada sedikit sumber. Alih bahasa Susi Septaviana R. Norway: The Atlas Alliance.

Semiawan, C. (1996). Perspektifpendidikan anak berbakat. Jakarta: Depdikbud

UNESCO. (2004). Changing teaching practices, using curriculum differentiation to respond to students Diversity. France : UNESCO

Wahab, R. (2009). Evaluasi kritis penyelenggaraan pendidikan anak berbakat di Indonesia dan arah pengembangannya ke depan sebagai implementasi Education for All. Solo: Makalah APPKhI

Yayasan Kinarya Didaktika. (2014). Cugenang gifted school. Cianjur: Yayasan Kinarya Didaktika 